\title{
LAS ANTOLOGíAS POÉTICAS Y SU ROL EN LA CONSTRUCCIÓN de una poesía (el Caso de TuCumán, Argentina)
}

\author{
Soledad Martínez-Zuccardi ${ }^{1}$ \\ Universidad Nacional de Tucumán, Argentina
}

\begin{abstract}
Resumen: El artículo propone un recorrido histórico por la construcción de la poesía de Tucumán (Argentina) a partir de un escasamente estudiado corpus de compilaciones y antologías poéticas publicadas en la provincia entre 1916 y 1967. Los propósitos de compiladores y antólogos, los criterios adoptados para reunir textos, la manera de disponer tales textos en cada volumen, las relaciones que los distintos libros establecen entre sí, son algunas de las variables analizadas. Gestos diversos se observan en el recorrido trazado, como, entre otros, el afán de elaborar un discurso fundacional y de carácter oficial acerca de Tucumán en los años del Centenario de la independencia nacional, o el gesto de "historizar" la poesía local y de seleccionar, según criterios excluyentes, poemas representativos de los períodos propuestos por una antología de los ' 60 .

Palabras clave: Antologías; Centenario de la independencia; década del 60'; poesía; provincia.

Recibido: 05 de enero de 2019

Aprobado: 27 de febrero de 2019

\section{POETIC ANTHOLOGIES AND THEIR ROLE IN THE CONSTRUCTION OF A LOCAL POETRY (TUCUMÁN, ARGENTINA)}

\begin{abstract}
This article proposes a history of the process of construction of the poetry of Tucumán (Argentina), focused on a scarcely studied corpus of poetic anthologies and compilations published in the province between 1916 and 1967. The purposes of anthologists and compilators, the criteria adopted in gathering and selecting poems, the way in which those poems are ordered and disposed in each volume,
\end{abstract}

\footnotetext{
${ }^{1}$ Soledad Martínez Zuccardi es Doctora en Letras por la Universidad Nacional de Tucumán, donde se desempeña como docente de Literatura Argentina II. Es investigadora del Consejo Nacional de Investigaciones Científicas y Técnicas de Argentina (CONICET) y autora, entre otros libros, de En busca de un campo cultural propio. Literatura, vida intelectual y revistas culturales en Tucumán (1904-1944) (Corregidor, 2012), así como de numerosos artículos sobre literatura y cultura de Tucumán y del NOA, y sobre poesía de autores argentinos. Correo electrónico: msoledadmartinezzuccardi@gmail.com
} 
the relationships between the different books, are some of the aspects which guide the analysis. Certain gestures can be observed in that process, like, among others, the ambition of elaborating a foundational and official discourse about Tucumán in the years of the Centennial of the National Independence, or the gesture of designing the chronology of local poetry and selecting (folowing strict criteria) representative poems of the moments and periods proposed by an anthology from the 1960s.

Keywords: Anthologies; Centennial of the National Independence; poetry; province; 1960s.

Un modo posible de transitar la historia de una poesía es recorrer sus compilaciones y antologías, volúmenes que suelen proponerse a sí mismos como reuniones de textos representativos de una poesía dada (la poesía de un determinado espacio, de una época, una generación, un grupo, una estética, un tema). En el caso de la poesía producida en la Argentina, estudios aparecidos de modo relativamente reciente se han ocupado de esbozar un panorama en cierto punto histórico por antologías poéticas argentinas (como el trabajo de Fernando De Giovanni referido al siglo XIX, o el de Aníbal Salazar Anglada centrado en la primera mitad del siglo XX). En realidad deberíamos hablar de antologías y compilaciones autodenominadas argentinas aunque están prácticamente restringidas a la capital del país. Como muestra Hugo Achugar en su artículo sobre los "parnasos fundacionales" hispanoamericanos, esas recopilaciones de la primera mitad del siglo XIX que aspiraban a construir una unidad ideológica y cultural -y a contribuir, de ese modo, a consolidar el proyecto de país de los incipientes estados nacionalescomienzan con la exclusión. Achugar propone un ejemplo tomado precisamente del ámbito argentino: la Lira argentina de 1924, nuestro "parnaso fundacional", que reúne una "totalidad" bonaerense pero se llama a sí misma "argentina" (Achugar 24). Se trata de una sinécdoque muy frecuentada $-y$ no por ello menos violenta- consistente en usufructuar el nombre del país para calificar la producción literaria de Buenos Aires. Puede decirse, de modo general, que en la Argentina las compilaciones y antologías poéticas han sido pensadas en relación con la nación más que en relación con las provincias. Algunos autores, sin 
embargo, han llamado la atención sobre la proliferación de antologías regionales y provinciales a partir de mediados del siglo XX. ${ }^{2}$

Este artículo propone pensar un corpus -hasta el momento no articulado como tal- compuesto por seis volúmenes que entre 1916 y 1967 aparecen en la provincia argentina de Tucumán y que de distintos modos se configuran como reuniones de la poesía tucumana. Poco más de cincuenta años transcurren entre la publicación del primero de ellos y del último, un período cuya apertura y cuyo cierre coinciden con dos momentos históricos de particular significación para Tucumán y que, al mismo tiempo, ubican a la provincia en un lugar de especial visibilidad en el imaginario nacional. Por un lado, 1916, fecha de celebración del Centenario de la independencia argentina, que en Tucumán motiva festejos que alcanzan una notable repercusión, en tanto sede de la declaración de la independencia en 1816 (en 1916 se publica, precisamente como parte de dichos festejos, Tucumán al través de la historia. El Tucumán de los poetas, compilación de las obras en verso referidas a la provincia). Por otro lado, el período se cierra en los años de aguda crisis económica y social ocasionada en 1966, durante la dictadura de Juan Carlos Onganía, por el cierre de once de los veintisiete ingenios azucareros de la provincia, cuya economía giraba predominantemente en torno a la industria del azúcar. En respuesta a esta crisis, en 1967 un grupo de autores publica Veinte poetas cantan a Tucumán como un modo de cantar a la provincia herida por las medidas del gobierno nacional. 1966 es a su vez -y quizá paradójicamente- el año de la celebración de los ciento cincuenta años de la declaración de la independencia; para conmemorar dicho acontecimiento surge entonces la Antología poética de Tucumán en el sesquicentenario. El corpus se completa con Florilegio de poesías tucumanas (1921), Primera antología poética de Tucumán (1952) y Poesía de Tucumán, siglo $X X(1965) .^{3}$

${ }^{2}$ María Amelia Arancet Ruda (2016) ha realizado un trabajo específico sobre antologías provinciales. Por su parte, Aníbal Salazar Anglada (2009:28) alude brevemente a la existencia de antologías en las provincias de lo que denomina como el "interior" del país a partir de la década de 1930.

${ }^{3}$ Este corpus no ha sido estudiado con anterioridad; la crítica precedente se ha ocupado muy brevemente de algunos de los volúmenes que lo integran. Así, valiosos trabajos panorámicos sobre la poesía y la literatura en Tucumán y en la región surgidos en las décadas de 1970 y 1980 (Billone, Lagmanovich, Corvalán) incluyen sucintas referencias al respecto. De forma más reciente, un 
Con anterioridad he estudiado algunos de estos libros desde la perspectiva del modo como sus textos representan a la provincia de Tucumán (Martínez Zuccardi "Poesía y azúcar", Martínez Zuccardi "El Centenario"). En esta ocasión, propongo, en cambio, examinar el corpus en su conjunto y desde otro ángulo: me interesa explorar el gesto mismo de compilar y de "antologar", de recopilar y seleccionar textos, la manera de disponerlos en cada volumen, los criterios adoptados, la lógica y la coherencia de cada libro, los objetivos de compiladores y antólogos -tanto los declarados en los paratextos como aquellos que la propia selección de poemas revela-, y examinar, al mismo tiempo, las relaciones que los distintos libros establecen entre sí. ${ }^{4} \mathrm{El}$ análisis de estas operaciones de construcción de los volúmenes permite establecer distinciones, según intentaré mostrar, entre aquellos que pueden ser considerados antologías y aquellos que no constituyen estrictamente antologías en el sentido moderno del término, por cuanto no prevalece el criterio de selección que la crítica (Núñez, Ruiz Casanova) menciona como condición casi indispensable -y razón de ser- de las antologías. Bajo esta luz, planteo a continuación un recorrido por el corpus y por los roles desplegados por los libros que lo integran en la construcción de lo que podría denominarse como una "poesía de Tucumán".

\section{Una compilación fundacional y la elaboración de un imaginario so- bre la provincia en los años del Centenario}

Esta suerte de recorrido histórico podría comenzar en 1916 con la publicación de Tucumán al través de la historia. El Tucumán de los poetas, compilación realizada por Manuel Lizondo Borda, poeta e historiador tucumano. ${ }^{5}$ Obra organizada en dos tomos, interesa aquí el segundo, que recoge composiciones en verso de treinta y dos autores,

estudio de Fabiola Orquera se detiene en Veinte poetas cantan a Tucumán junto a otros discursos que elaboran simbólicamente la mencionada crisis de 1966.

${ }^{4}$ Este modo de pensar el corpus se nutre en buena medida de los señalamientos brindados por José Francisco Ruiz Casanova en su estudio sobre la "poética de la antología poética", que propone parámetros de análisis para el examen de este tipo de volúmenes.

${ }^{5}$ Abogado egresado de la Universidad de Buenos Aires, Lizondo Borda se destacaría con el tiempo sobre todo como historiador. Ramón Leoni Pinto le dedica un lugar relevante en su estudio sobre la historiografía local y afirma que en sus más de treinta libros, Lizondo Borda escribió la historia de la provincia desde sus orígenes hasta la década de 1930, dando una visión integral de la vida provincial y regional (Leoni Pinto 80-85). Su primer libro, sin embargo, es de poesía: El poema del agua, de 1908 . 
desde Martín del Barco Centenera (siglo XVII), a escritores y figuras públicas de los siglos XIX y comienzos del XX (Fray Cayetano Rodríguez, José Agustín Molina, Marco Manuel Avellaneda, Paul Groussac, Esteban Echeverría, Adán Quiroga, Mario Bravo, Leopoldo Lugones, Ricardo Rojas, por mencionar solo algunos). ${ }^{6}$ Este volumen niega ser una antología. El breve texto con que se abre, titulado "Dos palabras" y firmado por "El recopilador", advierte al lector que el libro no es una "selecta antología" en donde "hallar y ver brillar [...] piedras preciosas de la literatura". La obra es definida, en contraste, como una "compilación sencilla, de carácter histórico, sobre todo cuanto en verso se ha dicho de Tucumán o de cosas tucumanas, a lo largo de los años..." (Lizondo Borda 5, énfasis mío). He subrayado el término "todo", que sugiere un afán totalizante y da cuenta de un gesto más ligado a la acumulación que a la selección. Por este motivo resulta difícil, en efecto, describir este libro como una antología, en la que precisamente es el principio de selección el que define los límites del conjunto (Ruiz Casanova 121).

Por otra parte, el criterio que rige la compilación parece ser históricotemático. Lizondo Borda reúne textos que hablan sobre Tucumán, como él mismo lo declara en el breve paratexto inicial -y de hecho si se revisa el conjunto de los textos incluidos se advierte que todos ellos tienen como objeto a Tucumán o bien diversos aspectos de la vida en la provincia-, y los ordena cronológicamente. El índice está organizado en tres partes, de acuerdo a la fecha de procedencia de los textos: la primera corresponde al siglo XVII, la segunda al siglo XIX y la tercera al XX (no hay textos del siglo XVIII). Además, el objetivo último de la obra parece ser la fundación de un imaginario sobre Tucumán, un objetivo, si se quiere, más histórico-político que específicamente literario. Este rasgo también aleja a Tucumán al través de la historia. El Tucumán de los poetas del dominio de las modernas antologías, que se caracterizan por tener a la literatura como un fin en sí mismo y no ya como función ancilar de otro orden, sea político o religioso. Así lo ha

\footnotetext{
${ }^{6} \mathrm{El}$ primer tomo reúne, en cambio, textos en prosa: escritos, informes y documentos coloniales que aluden a la región del Tucumán, numerosas crónicas de viajeros que visitaron la provincia, fragmentos de las memorias de Juan B. Alberdi y Gregorio Aráoz de Lamadrid, escritos de Domingo F. Sarmiento, páginas literarias de Juana Manuela Gorriti, textos de Paul Groussac, entre otros.
} 
sugerido Estuardo Núñez, para quien en el caso hispanoamericano no puede hablarse de antologías en sentido estricto hasta el siglo XIX (260261). No obstante, y como explico más adelante, hay en la compilación un objetivo segundo de orden ya propiamente literario.

Pero retomando el primer objetivo, de carácter histórico-político, creo que él puede entenderse en el marco del encargo oficial del que surge la compilación, ordenada, según lo anticipado antes, como parte de los festejos del Centenario por parte de la Comisión Provincial del Primer Centenario de la Independencia Argentina. Los integrantes de esta comisión eran en su mayoría -aunque no exclusivamentemiembros de la elite política y socioeconómica tucumana, y muchos de ellos formaban parte además de un grupo que en el marco de la historiografía local ha sido denominado "generación del Centenario" o "generación de la Universidad" y que dio impulso a un vasto proyecto de modernización económica y cultural de la provincia, tendiente a convertirla en el centro de la región del Noroeste argentino y en un importante polo a nivel nacional. De inédita inclinación por la acción cultural, además de conducir asociaciones científicas y literarias y de fundar revistas culturales, este grupo se encargó de la creación de la Universidad de Tucumán, la primera universidad del norte de la Argentina, fundada en 1909 e inaugurada en 1914. Juan B. Terán, un miembro central de este grupo y en la época rector de la flamante casa de estudios, es precisamente quien dirige a Lizondo Borda en la realización de la compilación, como lo destaca el mismo compilador en el prefacio del primer tomo.

Así, Tucumán al través de la historia. El Tucumán de los poetas se inscribe en el marco de una más vasta labor impulsada por el mismo grupo del Centenario y sustentada en el afán de reunir y publicar escritos y documentos relacionados con Tucumán. Se trata del momento de elaboración de un discurso histórico oficial, en el que comienza a organizarse el Archivo Histórico de la Provincia y en que ven la luz importantes publicaciones oficiales o universitarias, ligadas todas a la historia provincial o a la realidad local. ${ }^{7}$ Se conforma así una suerte de

\footnotetext{
${ }^{7}$ Publicaciones como Tucumán y el Norte argentino (1910) de Juan B. Terán, Tucumán antiguo (1916) de Julio López Mañán, los cinco libros de Ricardo Jaimes Freyre aparecidos entre 1909 y 1916: Tucumán en 1810, Historia de la República de Tucumán, El Tucumán del siglo XVI, 
movimiento de investigación en torno a la historia de Tucumán, que supone el punto de arranque de la "historia científica en la provincia" (Leoni Pinto 71). Además, si se toma en cuenta el contenido de los textos compilados por Lizondo Borda (que componen la silueta de un Tucumán edénico, rico y feliz, dueño de un heroico pasado de gloria así como de un porvenir brillante a partir de la pujanza de su industria azucarera)se advierte que ellos diseñan una representación casi sin fisuras de la provincia, afín al espíritu celebratorio y optimista que recorre la Argentina en el momento de cumplir sus primeros cien años de vida institucional y que, como he analizado en un trabajo anterior, resulta estratégica en relación con el mencionado proyecto de grupo del Centenario.

La compilación reviste un carácter fundacional por cuanto reúne en un volumen, probablemente por primera vez, textos poéticos referidos a Tucumán que se encontraban dispersos en folletos, periódicos, revistas, ediciones de autor. ${ }^{8}$ En este sentido, la obra podría ser pensada en relación con los antes mencionados "parnasos fundacionales" de los que habla Achugar -aunque para referirse a un período muy anterior y considerando a la nación en conjunto-.Tucumán al través de la historia. El Tucumán de los poetas configuraría una suerte de parnaso fundacional local que, al servicio -en principio- del proyecto que el grupo del Centenario tiene para Tucumán, aspira a forjar un imaginario sobre la provincia y sobre el lugar de la provincia en la nación.

El afán de fundar un discurso sobre Tucumán parece primar, así, por sobre el de fundar una literatura o una poesía de Tucumán. De todas maneras, entiendo que hay en la obra un objetivo segundo que, según lo anticipado, tiene que ver ya con el orden específicamente literario. Este objetivo está explicitado por Lizondo Borda en el breve paratexto inicial, donde piensa al libro como un aporte a lo que llama "la historia futura de la poesía tucumana”. Al definir su libro afirma: "Es también,

El Tucumán colonial, Historia del descubrimiento de Tucumán, las ediciones oficiales realizadas durante la gestión de Ernesto Padilla: El Congreso de Tucumán, de Paul Groussac, el lujoso Álbum del Centenario, la propia compilación de Lizondo Borda que aquí nos ocupa.

${ }^{8}$ En el caso de los textos de autores que no proceden de Tucumán, algunos de ellos son extraídos de otras compilaciones de poesía argentina del momento, como sobre todo la realizada por Juan de la Cruz Puig en ocasión de la celebración del Centenario de 1810, Antología de poetas argentinos, publicada en Buenos Aires en 1910. 
-o pretende ser, como también puede verse por la mayor suma de autores tucumanos que figuran en él-, un a modo de pequeño aporte que a la historia futura de la poesía tucumana se ha querido prestar" (Lizondo Borda 5). Así, el autor distingue en el conjunto de la recopilación una zona configurada por textos de autores tucumanos a la que denomina "poesía tucumana". Aunque no los menciona en ese breve texto, la revisión del volumen permite identificar como representantes de esta zona a los siguientes nombres de autores de la provincia (nacidos o residentes allí en el momento):el obispo José Agustín Molina, Santiago Vallejo, Josefa Díaz, Patricio Gallo, Damián Garat, Pedro Berreta, Mario Bravo, Delfin Valladares, Alberto Mendióroz, Amalia Prebisch, Víctor Toledo Pimentel, Salustiano Zavalía, Ramón Cordeiro, Fausto Burgos, Valentín de Pedro y el propio Lizondo Borda.

Hay además una "Advertencia final", firmada también por "El recopilador", en la que este lamenta la ausencia de ciertos "autores familiares a nosotros", motivada en el hecho de no haber encontrado "composiciones suyas adaptables al objeto de esta obra", esto es, poemas referidos a Tucumán. Allí menciona a Ricardo Jaimes Freyre y Germán García Hamilton (provenientes de Bolivia y de Uruguay respectivamente), a Ricardo Casterán y José Lucas Penna (presentados como "poetas recientes"), a Octavio Lobo (muy joven en el momento y descripto como "bella esperanza de mañana"), y a Silvano Bores y Alberto Soldati ("poetas tucumanos de ayer"). Llamo la atención sobre esta advertencia por cuanto estos autores parecen ser nombrados por Lizondo Borda, aunque no lo plantea en esos términos, en tanto autores significativos de la poesía tucumana, ese campo a cuya futura historia aspira a contribuir. En la referencia a estas figuras ya no prima el criterio temático que rige el conjunto de la compilación sino el afán de aportar a la configuración de una poesía. De alguna manera se está sugiriendo que estos autores recordados en la "Advertencia final" deberían ser tomados en cuenta para pensar la historia de la poesía de Tucumán, junto con los autores tucumanos antes mencionados, cuyos textos sí se incluyen en la compilación.

Por otra parte, cabe, en este punto del análisis, notar que si bien el objetivo literario aparece como un objetivo segundo, ello no significa 
que el compilador no reconozca la especificidad de lo literario o no posea competencias para hacer un juicio crítico en torno a la calidad de los textos seleccionados. Por el contrario, Lizondo Borda parece decidir o elegir hacer otra cosa y se muestra consciente de no estar otorgando al plano estético un lugar preponderante. De allí esa advertencia inicial al lector de no pretender hallar en su "sencilla" compilación "piedras preciosas" de la literatura. Pero en otras breves intervenciones paratextuales como en las notas con las que presenta los textos incluidos, demuestra su competencia literaria o su capacidad para establecer relaciones entre los poemas recopilados y la obra de autores clásicos. Así, elucubra acerca de las razones de los "defectos rítmicos" de un poema de la década de 1830 (Lizondo Borda 39), cuestiona los juicios críticos realizados sobre la poesía de Marco Manuel Avellaneda y declara que "por su fondo y su forma", sus textos "son mejores" que los de "muchos de sus contemporáneos" (35), aclara que el texto incluido del Obispo Molina carece de "valor poético" pero "nos da en algunos puntos detalles históricos preciosos" (19). Presenta además a Molina como "nuestro primer poeta tucumano", un señalamiento que entiendo debe vincularse con ese afán de contribuir a la futura historia de la poesía tucumana. Con respecto a la valoración de influencias literarias, reconoce "un cierto dejo a la fluidez y mística dulzura de San Juan de la Cruz" (65) en Santiago Vallejo, de quien afirma que "fue sin duda quien mejor dominó el verso en el Tucumán de su tiempo" (65), esto es, de fines del siglo XIX. De Josefa Díaz "poetisa tucumana de hace tiempo, hoy poco menos que desconocida", dice que sus versos "no son muy hermosos pero son correctos" (75).

\section{Mostrar el "talento tucumano": una temprana antología de 1921}

Es posible pensar que esa finalidad específicamente literaria de construir una poesía de Tucumán que, como acabamos de ver, estaba larvada en tanto más bien tímido objetivo segundo en la compilación de Lizondo Borda, encuentra un lugar preponderante en Florilegio de poesías tucumanas, libro aparecido un lustro después. Realizado por Alfredo Cónsole -bibliotecario y periodista tucumano-, no se trata ya de una publicación oficial sino de una edición del autor. ${ }^{9} \mathrm{Si}$ el libro de

${ }^{9}$ Cónsole fue bibliotecario de la Biblioteca Alberdi y secretario del Ateneo de Tucumán. Co- 
Lizondo Borda ofrece un perfil más político-histórico que literario, y tiene como principal propósito el de forjar un discurso fundacional sobre Tucumán, la antología de Cónsole, por el contrario, está más directamente orientada a construir una poesía tucumana. Si Lizondo Borda funda un imaginario, Cónsole funda una poesía.

Así, en tanto sus objetivos y sus criterios son específicamente literarios, Florilegio de poesías tucumanas puede considerarse una antología. Una antología de tipo general y panorámica, que reúne textos de poetas nacidos en Tucumán y "de aquellos que habiendo nacido en otras provincias cantan entre nosotros los primores de esta tierra", como afirma el autor en el prefacio (Cónsole, Florilegio 12). Esta última aclaración permite advertir que Cónsole sigue en parte, aunque no exclusivamente, el criterio temático que prevalece en la compilación de Lizondo Borda. En sintonía con su carácter de antología panorámica, los textos configuran un conjunto heterogéneo desde el punto de vista estético, en el que se cruzan la poesía clásica con la modernista, o la poesía orientada a la celebración patriótica y la de tono íntimo entre otros aspectos.

El citado prefacio establece como propósito "recordar a los poetas de ayer y presentar a los de la nueva generación en un rimero de páginas selectas que permita apreciar el talento tucumano" (12). Expresiones como "talento" y "páginas selectas" subrayan la importancia otorgada a la selección, así como la presencia de un criterio fundamentalmente estético. Ello contrasta con el afán de acumulación recientemente considerado en relación con la compilación de Lizondo Borda y con su advertencia acerca de no buscar allí "piedras preciosas" de la literatura. Interesa reparar también en el término "florilegio" elegido por Cónsole para dar nombre a su libro, un término históricamente muy utilizado en compilaciones de poesía española e hispanoamericana y que está ligado al significado etimológico de "antología": "acción de elegir o seleccionar flores" (Ruiz Casanova 34). Así, y a diferencia de Lizondo Borda, Cónsole sí parece querer buscar "piedras preciosas", "flores" cuidadosamente escogidas en tanto muestras de "talento" poético.

laboró en los diarios La Gaceta y El Orden, además de editar en Tucumán el Florilegio y unas Impresiones de viaje (1920). Luego se radicó en Buenos Aires, donde publicó libros sobre todo de bibliotecología. 
Si se considera el conjunto de los textos que componen ambos volúmenes, se observa que Cónsole selecciona poemas de muchos autores incluidos antes por Lizondo Borda (los ya mencionados Molina, Vallejo, Díaz, Gallo, Berreta, Bravo, Burgos, Valladares, Mendióroz, Prebisch, Toledo Pimentel, Lizondo Borda, Zavalía, Cordeiro, de Pedro). ${ }^{10}$ Sin embargo, y descontando algunas pocas excepciones, los textos elegidos son diferentes. Además, Cónsole incluye mayor cantidad de poemas de cada autor. A su vez, agrega más de una docena de autores que no estaban en el volumen precedente. Sucede que, si bien transcurren solo cinco años entre la publicación de un libro y el otro, en ese lapso se edita una cantidad para el momento considerable de poemarios en Tucumán, en su mayoría de autores nuevos. Así lo revela el mismo listado de "Obras poéticas de autores tucumanos" que Cónsole da a conocer al final de su antología. Del total de veinte títulos de los que consta esta lista, once aparecen entre 1916 y 1920, esto es, luego de la publicación de Tucumán al través de la historia. El Tucumán de los poetas. Por su parte, los primeros libros del listado - que figuran entre los primeros libros de poesía publicados en Tucumán (Billone 1617)-datan de pocos años antes: Las edades (1908) de Toledo Pimentel y El poema del agua (1909) de Lizondo Borda. Puede notarse, de ese modo, que tanto la compilación de Lizondo Borda como la antología de Cónsole surgen en una etapa todavía liminar en la actividad poética de la provincia.

Entre los textos de autores nuevos incluidos en el Florilegio, se cuentan poemas del propio Cónsole y de Segundo M. Argañaras, Tránsito Cañete de Rivas Jordán, Ricardo E. Casterán, Juan Carlos Frías, Arturo E. Guasch, Maximiliano Márquez Alurralde, José M. Ponssa, Miguel Tarzia, José Luis Torres, David Salmón Cadeneau, Mercedes Maciel Ledesma, Luis Eulogio Castro, Raúl Paverini, Octavio E. Lobo. Estos cinco últimos, autores noveles en la época, serían considerados posteriormente por el mismo Cónsole -en un estudio que publica en 1941 en la revista

${ }^{10}$ Llama la atención la ausencia de Garat, que sí estaba en el volumen precedente, ya que, si bien se trata de un autor entrerriano que había residido en Tucumán algunos años, tiene poemas ligados a la provincia. Tampoco están presenten otras figuras significativas entonces residentes en Tucumán, como el boliviano Jaimes Freyre o el uruguayo García Hamilton, que son mencionados por Lizondo Borda en la advertencia final de su compilación, aunque no incluidos en ella por razones temáticas, como tampoco aquí, probablemente por el mismo motivo. 
tucumana Sustancia-como parte de un grupo surgido en 1919 que supone un "florecimiento literario" en la provincia. Integrarían ese grupo poetas entonces menores de veinte años y que mueren o se suicidan en plena juventud. Los llama, por lo tanto, los "poetas tucumanos malogrados por la muerte" (Cónsole "Los poetas" 653). El Florilegio precisa y a la vez amplía lo que Lizondo Borda había insinuado como objetivo segundo: contribuir a la historia de la poesía tucumana. Y uno de sus aciertos es la incorporación de esa poesía entonces tan reciente, un gesto que revela la aptitud de Cónsole para captar la producción del presente y su decisión de incluirla como parte de lo que entiende como poesías tucumanas selectas. Además de los "malogrados", el autor incluye otros poemas nuevos, como los premiados el mismo año de publicación del Florilegio en los juegos florales locales (pertenecientes a los ya mencionados Cañete, Casterán, Tarzia).

Otro aspecto valioso de la antología es su prefacio, un interesante estudio sobre la historia de la poesía tucumana que delimita momentos, emite juicios estéticos y propone una periodización. El texto comienza planteando que la extraordinaria belleza de la tierra tucumana la convierte en ámbito propicio para la poesía y afirma que allí la poesía artística es cultivada con entusiasmo pese a la "frialdad del ambiente". Alude a la existencia de precoces vocaciones literarias que ante la "falta de estímulo" no tardan en "abandonar la lira" (Cónsole, Florilegio 7). Juzga que a esta situación se debe "la carencia de una labor colectiva que muestre toda la potencia del talento tucumano; las flores desparramadas aquí y allá apenas dan la sensación del espléndido vergel" (8). La última frase supone una descripción de la propia obra en la que retoma la noción de seleccionar flores, presente en el título elegido para la antología. Y supone además una negación de labores colectivas previas, como, podríamos pensar, la compilación de Lizondo Borda, no mencionada en el prefacio, quizá porque Cónsole no piensa su propia antología en línea con la tarea iniciada por esa compilación. ${ }^{11}$

\footnotetext{
${ }^{11}$ De todos modos, Cónsole menciona a Tucumán al través de la historia. El Tucumán de los poetas en la bibliografía final, como fuente de la que se ha tomado "parte del material que forma este libro", según consigna el subtítulo. Y, por otra parte, incluye en su Florilegio poemas de Lizondo Borda, a quien elogia en las breves referencias con las que presenta los textos: afirma, que su segundo libro, El amor innumerable, "ha confirmado su prestigio de poeta" (97) y en el prefacio califica El poema del agua de Lizondo Borda como un "hermoso poema" (11).
} 
En cuanto a su propuesta de periodización, el prefacio distingue lo que podríamos denominar como cuatro momentos de la poesía tucumana, aunque Cónsole no los llama así. En el momento inicial (fines del siglo XVIII), el único tucumano que alcanza "prestigio de poeta" sería para Cónsole el obispo José Agustín Molina, a quien describe como un autor dotado de facilidad para la versificación celebratoria aunque poco preocupado por la calidad del resultado: "escribía versos de continuo en celebración de las efemérides religiosas y de los triunfos de la patria, sin preocuparse mayormente de la corrección de sus obras" (8). Del conjunto de su producción, destaca los villancicos, "llenos de mística dulzura". Un segundo momento se haría reconocible a comienzos del siglo XIX, cuando "la sociedad tucumana había despertado ya a la vida artística". Menciona las invitaciones a los bailes oficiales que escribía en verso ("ingenuos versos”) el gobernador Javier López y las "grandilocuentes odas de corte clásico" de Marco Manuel Avellaneda. Se abriría luego un "largo paréntesis en la incipiente poesía tucumana", que Cónsole vincula con las luchas civiles.

El tercer momento se perfilaría varias décadas después, a partir de la creación de la Sociedad Sarmiento en 1882 -asociación científica y literaria que promueve la vida intelectual de forma bastante sistemática para la época-. Santiago Vallejo es mencionado como el principal poeta de esta etapa, de "vasta cultura literaria" y cuyos versos "fluyen como agua de un cristalino manantial" (10). También son nombrados Patricio Gallo y Josefa Díaz, "acaso la primera tucumana que tuvo relaciones con las Musas" (10). El inicio del cuarto momento estaría marcado por el año 1905, en que un nuevo poeta, Pedro N. Berreta, resulta premiado en los juegos florales con un conjunto de sonetos titulados El poema de mi tierra. Se inicia entonces para Cónsole un "nuevo florecimiento lirico", en el que convergen quienes cultivan la poesía clásica (como Víctor Toledo Pimentel, quien gana los Juegos Florales de 1907 con su poema "Las edades") con aquellos, como Lizondo Borda, que adhieren a la estética modernista predicada por Jaimes Freyre. Menciona por otra parte a Mario Bravo cuyo "estilo sobrio" e "intensa emotividad" le han "proclamado poeta de las multitudes" (12). El prefacio sugiere la existencia de un quinto momento, en el que sin embargo Cónsole no se detiene -si bien selecciona textos de los poetas de este momento-, y 
que estaría marcado por la producción de autores noveles en la época de aparición del Florilegio, "algunos de los cuales empiezan a descollar prometiendo buena cosecha" (12).

En su estudio sobre la poética de la antología poética, Ruiz Casanova distingue como "dos formas textuales parejas pero disímiles" a los "prólogos propiamente dichos" de las advertencias, notas preliminares o justificaciones. Los primeros constituyen verdaderos estudios que, además de presentar las obras y los autores incluidos y justificar la selección, suelen ofrecer un cuadro histórico de la poesía en cuestión, una suerte de informe de la situación que habilita un espacio crítico e historiográfico para el propio libro y lo que él reúne. Las advertencias y afines, en cambio, suelen ceñirse únicamente a dar cuenta de la selección y del procedimiento del antólogo (177). Ambas formas textuales ratifican, por otra parte y junto con la selección misma, el carácter de autor del antólogo (179). El prefacio del Florilegio es un verdadero estudio, que perfila la figura de un antólogo estudioso y fino conocedor del entonces muy joven "poesía de Tucumán", tanto de su desarrollo global (que él mismo se ocupa de reseñar y en torno al cual propone una periodización) como de la obra de cada autor en particular (realiza distinciones entre los textos de un mismo poeta, formula valoraciones, juicios estéticos y hasta esboza críticas al respecto, según hemos visto). En ocasiones establece además comparaciones entre la producción de distintos autores y valora su diversa significación.

Ante la escasez de trabajos de esta índole en la época, el prefacio de Cónsole emerge como un estudio pionero sobre la poesía tucumana, en un momento en que aún no existía la crítica académica sobre la literatura local (que surgiría mucho después, a partir de las décadas de 1940 y 1950, como veremos más adelante). Por último, cabe notar que si bien el prefacio tiene una organización histórica, el conjunto de los textos seleccionados en la antología no sigue un orden cronológico sino alfabético, como si Cónsole quisiera que el lector se concentrara en las muestras de talento por él escogidas, sin tomar en cuenta momentos ni ubicaciones históricas, que ya están de todas maneras planteados en el prefacio. 


\section{Un concurso literario oficial y una autoproclamada "primera" an- tología}

Pasan varios lustros entre la publicación de la antología de Cónsole y la aparición de la que se llamaría a sí misma Primera antología poética de Tucumán (1952), pese a que no es, de hecho, la primera. En ese lapso la actividad literaria local experimenta notorias transformaciones, debidas en buena medida a la presencia en el ambiente de la Facultad de Filosofía y Letras de la Universidad Nacional de Tucumán, constituida como tal en 1939. La nueva Facultad promueve la formación de jóvenes escritores e introduce nuevas ideas y lecturas, a la vez que fomenta la exigencia de rigor y sistematicidad, tanto en la producción literaria como en la práctica crítica. Por esos años la literatura comienza a instituirse como un orden diferenciado y específico dentro del más vasto campo cultural. Surgen entonces revistas excluyentemente literarias como Cántico (1940), centrada en la joven poesía de provincias, y grupos como La Carpa, quizá la manifestación colectiva más significativa en la historia de la literatura del noroeste argentino. Entre los libros que La Carpa publica con su sello editorial se cuenta la Muestra colectiva de poemas (1944), que puede ser pensada como una temprana antología de la poesía norteña. ${ }^{12}$ Una antología programática y de grupo, destinada a dar a conocer los poemas iniciales de sus jóvenes integrantes. ${ }^{13}$

Volviendo a la Primera antología poética de Tucumán, se trata de una publicación oficial que deriva de un certamen literario organizado en 1951 por la Comisión Provincial de Bellas Artes ${ }^{14}$ (organismo encargado de la edición del libro) y en el que actúan como miembros del jurado el escritor santiagueño Bernardo Canal-Feijóo, entonces residente

${ }^{12} \mathrm{El}$ sello de La Carpa, dedicado a la publicación de libros sobre todo de poesía (y, en menor medida, de narrativa y ensayo) brinda cierta sistematicidad a la práctica editorial local que -en lo que atañe a la publicación de libros de literatura- se caracterizaba hasta el momento por la aparición, más bien aislada y en ediciones de autor, de libros sobre todo de poesía, como puede deducirse de los señalamientos de Billone en su recorrido por la actividad poética en Tucumán. Me limito aquí a mencionar la Muestra colectiva ... de La Carpa, a la que me he referido más extensamente con anterioridad (Martínez Zuccardi En busca de).

${ }^{13}$ Basándose en la clasificación propuesta por Marcelino Menéndez Pelayo, Ruiz Casanova distingue las antologías panorámicas (que suelen ser de carácter general, diacrónico e histórico) de las programáticas, que en su mayoría responden a un grupo o generación y suelen ser sincrónicas (132-133).

${ }^{14}$ Dicha comisión había surgido a mediados de la década de 1930, durante el gobierno del radical Miguel Campero, y desde 1938 venía organizando los certámenes literarios. 
en Buenos Aires, el crítico literario Alfredo Roggiano y el filósofo Manuel Gonzalo Casas. Los últimos se desempeñaban en la época como profesores de la Facultad de Filosofía y Letras tucumana. ${ }^{15}$ Los textos galardonados en el certamen son los que componen la antología, que se encuentra organizada según la jerarquía de los premios. La encabezan los poemas de los tres autores que comparten el Primer Gran Premio: Raúl Galán, Guillermo Orce Remis y un entonces casi adolescente Tomás Eloy Martínez. Siguen los textos de quienes obtuvieron el Primer Premio Especial (Eduardo Joubin Colombres y Rogelio Arana) y el Primer Premio Mención (Emilio Rubio Hernández, Alicia Antonietta, Segundo M. Argañaraz, Carola Briones, Marina Briones, Emilio Carilla, entre otros, que aparecen en el libro según un orden alfabético). ${ }^{16}$ En total son veintiún autores -de cada uno se incluye entre uno y tres poemas-Ellos componen un conjunto heterogéneo integrado por poetas tanto jóvenes como de generaciones anteriores, por figuras que habían trazado significativas trayectorias -o que con el tiempo las trazarían- y otras que podrían calificarse más bien como escritores aficionados.

Si nos concentramos en el caso de quienes obtienen el galardón más importante, se advierte que Galán y Orce Remis son figuras que en la época gozaban ya de consagración en el ámbito de la poesía local (Galán en tanto líder de La Carpa, Orce Remis en tanto autor de libros premiados), mientras que Martínez iniciaba recién su trayectoria como escritor (precisamente este concurso y esta antología suponen su ingreso a la escena literaria). También el conjunto configurado por los poemas

\footnotetext{
${ }^{15}$ Caben aquí breves consideraciones sobre los integrantes del jurado. Canal-Feijóo era en la época un escritor consagrado que había participado activamente en la vida literaria de Buenos Aires, y había sido, además, uno de los pocos exponentes de la poesía vanguardista en el noroeste argentino, con su libro Penúltimo poema del fútbol, de 1924. Roggiano — que con el tiempo trazaría una vasta trayectoria en el ámbito de la crítica de la literatura hispanoamericana - unía a su condición de crítico y profesor de literatura la de autor, a partir de su libro de sonetos El río iluminado (1947), aparecido coincidentemente con su ingreso al medio tucumano (Billone 37). Más adelante daría a conocer un estudio sobre la poesía del noroeste argentino que se convertiría en un trabajo pionero en el área. En cuanto a Casas, él unía a sus preocupaciones filosóficas una fuerte "inquietud poética", por la que sería definido como un "filósofo-poeta" (Catturelli 19). Estaba además muy vinculado con varios poetas de Tucumán en la década de 1950 (Orce Remis 4).

${ }^{16}$ La lista se completa con los siguientes autores, todos galardonados con el Primer Premio Mención: Alba Defant Durant, Alma García, Roberto J. García, Odín Gómez Lucero, Ricardo C. Marcantonio, Maximilano Márquez Alurralde, Juan Eduardo Piatelli, Rubén C. Rodó, Oscar Emilio Sarrulle y Raúl Serrano.
} 
incluidos en la antología está signado por la heterogeneidad, en tanto convergen estéticas muy diversas, desde el intimismo neorromántico a un tono cercano a la denuncia social, desde la mirada puesta en la ciudad a los ámbitos del campo o del ingenio azucarero, entre muchos otros aspectos.

Por cuanto no enfoca en una estética o una generación en particular, este libro podría ser descripto, al igual que el de Cónsole, como una antología general, aunque, a diferencia del Florilegio, la Primera antología poética de Tucumán no tiene un carácter diacrónico ni histórico, sino que está enfocada en el momento presente, esto es, en las distintas manifestaciones poéticas del momento en Tucumán (tomando como punto de partida, eso sí, los textos de los autores que participan en el concurso). Porque, como puede advertirse, el libro está configurado de acuerdo con la lógica del certamen literario del que deriva. En ese sentido, parece más la publicación casi directa de los resultados del concurso que una antología gestada, pensada y organizada por un antólogo. De hecho, la figura misma de antólogo -en su carácter de autor del libro (Ruiz Casanova)- se torna escurridiza en el caso de este volumen. ¿Se trata de un autor colectivo conformado por los tres miembros del jurado? Es significativo en este punto que sus nombres no figuren en la tapa o en la portada del volumen en tanto autores (donde se consigna, en cambio, además del título del libro y de la fecha, sólo a la Comisión Provincial de Bellas Artes). ${ }^{17}$ ¿Sería, entonces, la comisión misma, en un caso de autoría colectiva institucional, la autora de la antología? ¿O tal vez el autor es quien actúa como representante de la Comisión en el jurado del certamen literario, esto es, Manuel Gonzalo Casas?

Lo cierto es que el discurso paratextual de antólogo es muy escaso en este libro. Se limita a un breve prólogo firmado por Canal-Feijóo, Casas y Roggiano, los tres miembros del jurado. No hay presentación de cada autor (como en el caso de El Tucumán de los poetas o del Florilegio de poesías tucumanas).Sí hay otros paratextos, ligados al carácter de

${ }^{17}$ Los nombres de los miembros del jurado aparecen, sí, como los firmantes del prólogo del libro y son mencionados nuevamente en una aclaración incluida en la última página: "Esta antología resulta del Certamen de Poesía organizado por la Comisión Provincial de Bellas Artes de Tucumán, Argentina. Actuaron como jurados: Don Bernardo Canal-Feijóo, Don Manuel Gonzalo Casas y Don Alfredo A. Roggiano". 
publicación oficial de la Primera antología poética de Tucumán, como listas de autoridades de la provincia (del gobernador al Subsecretario de Cultura) o breves notas destinadas a mencionar las instituciones que colaboraron en la edición del volumen, como el Instituto Superior de Artes de la Universidad Nacional de Tucumán y la imprenta de la misma Universidad. ${ }^{18}$

El prólogo mencionado es breve y de carácter general. Según la ya citada distinción de Ruiz Casanova entre prólogos propiamente dichos y advertencias o justificaciones, éste se aproxima más a la forma de las segundas. Luego de establecer una noción de poesía (como expresión de un modo de ser individual e intransferible por el que cada poeta da una visión de esencia propia y a la vez universal del hombre) y de poeta (al que se otorga un carácter demiúrgico), el texto fundamenta la elección del procedimiento del concurso literario como una manera de garantizar objetividad y, al mismo tiempo, de reunir una variedad de formas poéticas: "hemos creído necesario, para la formación de esta antología, registrar el resultado objetivo de un concurso en que se manifestaran todas las formas del quehacer poético del ambiente y la circunstancia histórica y cultural que lo representa" (Primera antología...8, énfasis mío). A continuación establece la calidad literaria (basada allí en el concepto de belleza) como único criterio de selección: "en todo momento hemos extremado nuestra voluntad para que presidiera nuestra selección única y exclusivamente el sentido de la belleza, la jerarquía de los valores de cada composición, con absoluta prescindencia de la persona del poeta, sus situaciones e ideas personales o cualquier otra relación extra poética". Declara, por último, aspirar a que el libro sea "una muestra colectiva de todas las manifestaciones de la poesía tucumana" (8, énfasis mío). Llama la atención la pretensión totalizadora sugerida en la reiteración del adjetivo "todas" que he subrayado en los fragmentos citados. Parece difícil pensar que un concurso pueda de hecho reunir la totalidad de las formas poéticas de un espacio determinado, cuando éste puede ser manifestación únicamente de la poesía de aquellos autores que hayan decidido participar en el concurso.

\footnotetext{
${ }^{18}$ También se nombra al artista húngaro radicado en Tucumán Luis Szalay como autor de las numerosas y bellas ilustraciones con las que cuenta el libro, editado por otra parte en gran formato.
} 
En el prólogo no hay referencia alguna a la historia ya recorrida por la poesía de Tucumán, como tampoco a compilaciones y antologías previas (como las de Lizondo Borda y Cónsole). Tampoco hay fundamentaciones en torno al título elegido para el libro, que supone una explícita autoproclamación como la "primera" antología de poesía aparecida en Tucumán. Pareciera así que el volumen hiciera tabla rasa con lo anterior. ¿Cuáles pueden ser las razones de este proceder? Resulta poco probable que se trate de desconocimiento. En todo caso, quizá, podríamos pensar que hay una opción por un punto de mira que toma en cuenta la poesía del momento y no la del pasado. En ese sentido, el libro es, tal vez, la primera antología del presente, que no aspira a mostrar la historia de la poesía de Tucumán sino a captar el estado de esa poesía en el momento presente, trazando un corte sincrónico.

Más allá de estos cuestionamientos que pueden hacerse a la Primera antología poética de Tucumán en cuanto a su coherencia constructiva, hay que rescatar otros aspectos, como la capacidad de captar tempranamente a un autor que luego desarrollaría una vasta obra narrativa reconocida internacionalmente como Tomás Eloy Martínez, o como el interés que reviste el libro y el concurso del que deriva para pensar la relación del campo literario local con el peronismo, y visualizar las diferencias entre la dinámica de éste y del campo porteño, como lo hemos hecho en otra ocasión (Martínez Zuccardi "La Primera antología").

\section{Dos antologías contrastantes y una iniciativa solidaria en los años 60}

En la década de 1960 el ámbito de la actividad poética se expande y complejiza. Aumenta en forma muy significativa el número de libros de poetas de Tucumán, tanto que se llega a hablar de una "verdadera avalancha de libros de poesía" a partir de 1960 (Billone41). Este hecho puede ser vinculado con la acción de proyectos editoriales que surgen en la época desde la esfera independiente (como la Peña El Cardón, creada en 1947 y que en los sesenta diseña su colección de "Poetas del Cardón") y desde organismos oficiales (como el Consejo Provincial de Difusión Cultural, instituido en 1959 por inspiración de Julio Ardiles Gray y cuya colección "Cuadernos del tiempo y su canto" publica alrededor 
de una docena de poemarios de autores jóvenes en el transcurso del decenio de 1960). En consonancia con esta ebullición poética, aparecen casi al mismo tiempo tres volúmenes que reúnen textos poéticos de autores locales: Poesía de Tucumán. Siglo XX (1965), Antología poética tucumana en el Sesquicentenario (1966) y Veinte poetas cantan a Tucumán (1967). A diferencia de algunos de los considerados antes, ninguno de estos tres libros responde a iniciativas estatales sino que se gestan en forma independiente. A continuación, me referiré brevemente a los dos últimos libros mencionados y luego me detendré solo en el caso del primero de ellos, que puede pensarse cabalmente como una antología en el sentido estricto del término y presenta una figura de antólogo particularmente consciente de su autoría y de la propia labor de selección y construcción.

Antología poética tucumana en el Sesquicentenario es editada por su autor, José A. Cresseri, quien al parecer no deja otros libros más allá de esta antología. ${ }^{19} \mathrm{El}$ volumen reúne poemas de treinta y ocho autores (entre dos y cuatro poemas de cada uno). No es una antología histórica sino que incluye textos de autores vivos en el momento de edición (con la única excepción de Lizondo Borda, entonces recientemente fallecido). Se trata de un amplio y diverso espectro de autores tucumanos o residentes en Tucumán, tanto jóvenes como maduros, incipientes como consagrados, y vinculados con distintas líneas estéticas. Algunos de ellos (Amalia Prebisch de Piossek, Valentín de Pedro, Lizondo Borda) ya habían sido incluidos en volúmenes muy anteriores como El Tucumán de los poetas y Florilegio de poesías tucumanas. Otros, en cambio, habían comenzado a publicar en los ' 40 y '50, como María Elvira Juárez, Carola Briones, Leda Valladares, Guillermo Orce Remis, Manuel Serrano Pérez, Eduardo Joubin Colombres, Manuel Aldonate, Juan José Hernández, Ariadna Chaves. Otros eran poetas incipientes o relativamente nuevos en el primer lustro de la década de 1960, como Néstor Rodolfo Silva, David Lagmanovich, Juan González, Arturo Álvarez Sosa, Tomás Eloy Martínez, Dora Fornaciari, Walter Adet, Jacobo Regen. ${ }^{20}$ Pero ese conjunto no está separado por criterios

\footnotetext{
${ }^{19}$ Cresseri actuó, por otra parte, en el campo de la música. Se encargó de musicalizar, por ejemplo, algunas letras para zambas, como las de Pedro Herrera (Juliá 30).

${ }^{20}$ La lista de autores incluidos se completa con Antonio Torres, Alma García, Leónidas 
cronológicos sino temáticos, como indico más adelante. No hay ningún tipo de presentación de los autores ni referencias biobliográficas. El principal paratexto de la antología es una breve "Nota preliminar" firmada por Cresseri con sus iniciales.

Como lo manifiesta el propio título, el libro celebra los ciento cincuenta años de la declaración de la independencia argentina. En tal sentido, se vincula con el volumen precedente de Lizondo Borda, surgido en conmemoración de los cien años del mismo hecho histórico. Y, al igual que esa compilación fundacional de 1916, la Antología poética tucumana en el Sesquicentenario parece tener también dos objetivos. Primero, un objetivo que podríamos llamar, siguiendo la terminología del propio volumen, "patriótico": Cresseri declara sentirse conmovido por la fecha de "grandes celebraciones" y afirma, en la mencionada nota preliminar, que de allí nace su antología, "compilada y editada en ofrenda al Sesquicentenario de la Independencia Nacional". De hecho, toda la primera parte del libro presenta una "temática inspirada en la Patria, sus orígenes, sus luchas, su fisonomía, sus héroes" y también "el lamento y la tristeza del poblador indígena" y el "surco fecundo hermanado al dolor del campesino". Una noción voluntariamente abarcadora de patria que lo lleva a decir "todo es Patria" (Cresseri 8). Pero la antología cuenta también con una segunda parte, denominada "Lírica tucumana" que va más allá de la coyuntura de celebración para recoger poemas de temas variados. Este sería el objetivo segundo, que podríamos describir como un objetivo literario. La segunda parte está separada a su vez en cuatro grupos, uno de ellos exclusivamente de "poetisas" -tal es el término que utiliza el autor-, destinado a que el lector pueda percibir más claramente el "grado de evolución" de la poesía escrita por mujeres en Tucumán. De hecho, esta antología es, de las aquí examinadas, la que mayor cantidad de autoras incluye.

No hay en la nota preliminar referencia alguna a los criterios de selección adoptados. Sí hay una definición de la propia antología como un "testimonio simple e informativo de nuestro caudal poético"

Martínez, Serafín Pazzi, Omar Estrella, Ricardo C. Marcantonio, J. Dionisio Campos, Juan Eduardo Piatelli, Ricardo Chirre Danós, Pedro Nacip Estofán, Salvador Heredia Luna, Carlos Cossio, Tomás García Giménez, Alfredo Roque Dall’Ara, Oscar Ramón Quiroga, Carlos Michaelsen Aráoz, Tiburcio López Guzmán y Lila Bru. 
(7-8), un testimonio destinado a "todo público", "de la obra de los autores incluidos, reflejando parcialmente las formas distintivas de su producción y procurando revelar las constantes de sus respectivos universos poéticos" (9). También pueden encontrarse algunos índices de la auto representación del antólogo, quien se muestra a sí mismo como un principiante o incluso un aficionado, al sugerir que con este libro incursiona en un terreno desconocido. Afirma, en efecto, que su deseo de hacer una ofrenda a la patria lo induce a realizar una "escabrosa empresa, quizás desusada a nuestra cotidiana actividad" (7).

Además de ser una fecha de celebración patriótica, el año 1966pasó a la historia de los tucumanos -quizá paradójicamente- como el momento de explosión de una crisis social y económica sin precedentes, ocasionada por el cierre masivo de ingenios azucareros mencionado al comienzo de este trabajo, drástica medida que supuso un cambio radical en el modo de vida de una parte importante de la población, y que actuó como una dolorosa herida infligida a una identidad tucumana históricamente ligada al azúcar. Y precisamente como una respuesta a esa mega crisis es que surge Veinte poetas cantan a Tucumán, una iniciativa de Carola Briones, Manuel Serrano Pérez y Carlos Duguech, quienes invitan a un conjunto de poetas a cantar a la provincia, como un modo de curarla simbólicamente de esa herida proveniente del gobierno nacional. El libro tenía además una finalidad solidaria, ya que proponía comprar leche en polvo con el dinero recaudado de la venta de ejemplares, para distribuir entre las familias de los obreros que habían quedado sin trabajo.

Y en torno a esta iniciativa solidaria se reúnen poetas disímiles, de distintas edades, grupos, y líneas estéticas pero que coinciden en aportar al libro poemas (uno por cada autor) que cantan a Tucumán (Manuel Aldonate, Arturo Álvarez Sosa, Carola Briones, J. Dioniso Campos, Luis A. Díaz, Carlos Duguech, Omar Estrella, Medardo L. Figueroa, Juan González, Pedro S. Herrera, Nicolás S. Leiva, Adolfo Manzano, José A. Moreno, Serafín Pazzi, Amalia Prebisch, Oscar Quiroga, Mario Romero, Manuel Serrano Pérez, Néstor R. Silva y Antonio Torres). La mayoría de los poemas están dedicados al azúcar y a los trabajadores del surco (un aspecto del que me he ocupado en trabajos anteriores). Se trata 
de una edición independiente, aunque cuenta con la colaboración del estado provincial a través del Consejo Provincial de Difusión Cultural y de la Universidad Nacional de Tucumán, a través de su imprenta y del Departamento de Artes. ${ }^{21}$

Resulta interesante el hecho de que este proyecto solidario y este afán de intervenir ante una situación crítica que sustentan al libro se realicen a partir de armas específicas, las de la poesía. En efecto, la poesía es pensada en el brevísimo prólogo del libro como un modo de intervención con fines a la vez simbólicos y materiales, como canto y como arma de lucha, como una comunión que hermana al poeta, al hombre y su contorno:

Los poetas pagamos fiera y desgarradamente este duro oficio de vivir y de tener abiertos los ojos a los dos precipicios de la angustia: el hombre que somos, y el contorno que nos rodea.

La palabra se moja en nuestra sangre y nos lleva estremecidos a todos los horizontes de la vida, nos hermana con el hombre, el paisaje, las cosas. [...] Pero hay un tiempo preciso para la poesía, cuando debe esgrimirse como un arma, o resonar plural a coro con las criaturas que comparten nuestra vida.

Aquí, en Tucumán, ahora viven tiempos difíciles quienes con mano generosa arrancan el azúcar y la miel de entre los verdes. [...]

Y los veinte poetas de este libro juntamos las monedas del canto para convertirlas en pan, en pájaros, en alegría... (Aldonate et als/n).

Cabe ahora detenernos, para terminar, en Poesía de Tucumán. Siglo $X X$, de Gustavo Bravo Figueroa, escritor y profesor de literatura tucumano, uno de los primeros egresados de la Facultad de Filosofía y Letras de la Universidad Nacional de Tucumán. ${ }^{22}$ Interesa mencionarla formación académica del autor, porque su libro es, en buena medida, fruto de esa formación, en especial su prólogo, como indico más ad-

\footnotetext{
${ }^{21}$ El libro está ilustrado por Aurelio Salas, Gladys Montaldo y Carlos R. Guchea.

${ }^{22}$ En un comienzo Bravo Figueroa se desempeña como docente en la Facultad de Filosofía y Letras tucumana, hasta que es dejado cesante durante el peronismo debido a su militancia en el Partido Socialista (Berreta 46). A partir de 1952 se convierte en presidente y principal motor de la Peña El Cardón, centro generador de la cultura provinciana y regional, hasta 2005, año en que es designado presidente de honor y en que, por otra parte, la Universidad Nacional de Tucumán lo distingue como "personalidad ilustre de las letras y la cultura". Es autor también de libros de poesía y de otra importante antología: 27 cuentos del norte argentino (1968).
} 
elante. Editada por el sello independiente Atenas, se trata de una antología panorámica y general, que se propone ofrecer al lector "una visión de conjunto y en profundidad" de la poesía de Tucumán en lo que entonces llevaba andado el siglo XX (Bravo Figueroa 25). Fundada en un criterio de historia literaria, la antología traza un recorrido por la poesía de la provincia desde comienzos del siglo hasta el momento de su publicación (1965).También responden a un criterio cronológico el prólogo y la organización misma de los poemas seleccionados, que aparecen agrupados según tres períodos: el primero (1901-1940) incluye textos de Ricardo Jaimes Freyre, Mario Bravo, Luis Eulogio Castro, Ricardo Chirre Danós, Víctor Toledo Pimentel, Manuel Lizondo Borda, Antonio Torres, Teresa Ramos Carrión, Rafael Jijena Sánchez, Juan Eduardo Piatelli; el segundo (1941-1955), de Raúl Galán, Julio Ardiles Gray, Eduardo Joubin Colombres, Omar Estrella, Manuel Aldonate, Guillermo Orce Remis, Leda Valladares, María Elvira Juárez, Nicandro Pereyra; el tercero (1956-1965), de Arturo Álvarez Sosa, Juan José Hernández, Juan González, David Lagmanovich, Dora Fornaciari, Ariadna Chaves, Tiburcio López Guzmán, Néstor Rodolfo Silva.

Este tercer y último período supone una selección de poemas del momento presente de la publicación, de autores en su mayoría jóvenes que más adelante se convertirían en poetas de significación pero que en la época comenzaban a dar a conocer su obra. En el caso de los autores de los dos primeros períodos, es posible advertir que esta antología no se destaca por la novedad, en el sentido de que no presenta autores que no estén incluidos ya en las compilaciones o antologías precedentes. Pero lo novedoso radica tal vez en la operación de selección de un número considerablemente menor de autores como los representativos de esos períodos, dejando de lado otros. Además, los textos seleccionados difieren en muchos casos. Una excepción en este punto está dada por la presencia de Jaimes Freyre, que no había sido incluido por Lizondo Borda ni por Cónsole. Bravo Figueroa, en cambio, no sólo lo incluye sino que en su prólogo lo destaca como la figura rectora del período 1901-1940.

Podría pensarse que Poesía de Tucumán. Siglo XX es la más "selecta" de las antologías y compilaciones consideradas hasta ahora, por 
cuanto presenta textos de un total de veintisiete autores para un período de sesenta años (un número reducido si lo comparamos, por mencionar tan solo dos casos, con los casi cuarenta autores de la antología de Cresseri, que se limita a "autores vivos", o los veintiún autores de la Primera antología poética de Tucumán, también circunscripta al momento del certamen literario del que deriva).Además, hay una condición para la inclusión de los autores en el volumen, condición calificada como "premisa insoslayable" por Bravo Figueroa en el prólogo: que "el poeta haya editado su obra", porque "precisamente, en el libro impreso trabaja el antologista", afirma el autor (24), sugiriendo la conciencia reflexiva con la que asume la propia tarea de antólogo. De cada autor se seleccionan estrictamente cinco poemas, lo que revela una cierta preocupación por el equilibrio del volumen en su conjunto.

Otros aspectos, de orden paratextual, sugieren esa conciencia de la labor de antólogo que muestra el autor, como la elaboración de notas biobibliográficas que presentan a cada uno de los poetas seleccionados. Una labor también presente, según vimos antes, en los volúmenes de Lizondo Borda y de Cónsole, pero que en la antología de Bravo Figueroa acusa mayor extensión y parece seguir criterios más precisos. En efecto, en todos los casos estas notas indican la fecha de nacimiento (y de muerte, cuando corresponde) de cada autor, datos sobre su actuación en el medio literario, la mención de los libros publicados, e incluso breves valoraciones o juicios críticos. ${ }^{23}$ Así, Bravo Figueroa dice, por ejemplo, que los poemas de Aldonate "se despreocupan de la forma para dar cabida a implicancias sociales" (73) y que Orce Remis es "uno de los más representativos de los líricos tucumanos" (103).

También puede pensarse como un índice de esa mencionada conciencia de antólogo, su preocupación por los antecedentes, esto es, por los volúmenes precedentes de su tipo, un gesto que contrasta, por ejemplo, con las antologías de Cónsole, Cresseri y, especialmente, la Primera antología poética de Tucumán, que prácticamente ignoran, como hemos visto, las antologías y compilaciones previas. Por el contrario, Bravo Figueroa comienza su prólogo con lo que Aníbal Salazar

\footnotetext{
${ }^{23}$ Resulta curioso que en el caso de las poetas mujeres, Bravo Figueroa no informa la fecha de nacimiento, probablemente como un gesto de galantería que deja entrever resabios de una cierta concepción patriarcal.
} 
Anglada denomina el "diálogo con la tradición antológica" (Salazar 26): el primer apartado del texto se titula "Anteriores antologías" y menciona la compilación de Lizondo Borda, el Florilegio de Cónsole y la Primera antología poética de Tucumán, así como selecciones de poemas más breves incluidas en artículos de revistas culturales, además de estudios previos sobre la poesía local publicados en medios periodísticos. Traza, así, una suerte de "estado de la cuestión" al respecto que sugiere de modo implícito la insuficiencia de esa tradición antológica y la consecuente necesidad de una nueva antología.

En realidad, la envergadura misma del prólogo es el aspecto que mejor revela la dedicación con la que Bravo Figueroa asume el gesto de "antologar". El texto -que por su rigor y sistematicidad podría leerse como un estudio en sí mismo, con consistencia propia- establece y fundamenta una propuesta de periodización de la historia de la poesía de Tucumán siguiendo en buena medida la teoría generacional del filólogo alemán Jules Peters en, quien considera ciertas variables para la conformación de un período generacional(las fechas aproximadas de nacimiento de figuras representativas en el medio literario, los elementos educativos, la experiencia de la generación, la presencia de líderes o guías, el lenguaje generacional). ${ }^{24}$ Desde esa óptica, Bravo Figueroa delimita los tres períodos mencionados antes (1901-1940, 1941-1955 y 1956-1965) y los caracteriza ampliamente. El primer grupo, que habría vivido al ritmo "de las tranquilas siestas provincianas" (Bravo Figueroa 11), tiene como foco de formación al Colegio Nacional y como figura líder a Jaimes Freyre. Su "lenguaje" es descripto como sentimental, decorativo, pintoresco y, a veces, pesimista. El segundo grupo, liderado por Galán, se formaría en la Facultad de Filosofía y Letras. Las principales experiencias generacionales serían el impacto de la Segunda Guerra Mundial, la guerra en España, la crisis de crecimiento político, industrial y económico de la Argentina y el fenómeno del peronismo. Predominaría en ese momento un lenguaje dionisíaco para expresar asuntos que giran en torno al hombre, sus problemas, sus nostalgias y esperanzas, y se advertiría, por otra parte, una relación entrañable

\footnotetext{
${ }^{24}$ La teoría generacional de este filólogo alemán, basada en la dialéctica hegeliana, influye en la crítica española a partir de la década de1930 y, en especial, a partir de su publicación en español en 1947 (Testaverde124-125).
} 
entre el poeta y su tierra. El tercer periodo, integrado por una "reciente promoción" no aglutinada en torno a un guía en particular, viviría la experiencia de un mundo en peligrosa tensión, una sensación de crisis generalizada traducida en una oscura angustia y un sentido pesimista de la vida. Dos serían los focos de formación: la universidad y el periodismo. El lenguaje presentaría una forma distinta, descarnada, hermética y estaría centrado más en los estados de conciencia, en problemas filosóficos y religiosos, que en el mundo exterior.

Luego de presentar esta propuesta de periodización, el autor desarrolla más extensamente cada una de las etapas, considerando la historia de la provincia, de sus instituciones culturales y educativas, sus revistas literarias y sus diarios, en ocasiones en relación con el desarrollo económico e industrial. Se explaya sobre las tomas de posición de algunos poetas y grupos, se detiene en especial en el caso de La Carpa y alude a las poéticas de ciertos autores. Menciona numerosos poetas, más allá de aquellos seleccionados en la antología. Esta suerte de ampliación de la propuesta - apoyada en ciertos casos en bibliografía referida a cuestiones contextuales locales o a la historia de la literatura argentina e hispanoamericana (de autores como Emilio Carilla o Enrique Anderson Imbert, por ejemplo) - contribuye a dotar al prólogo de envergadura propia.

El texto parece fruto de una investigación sistemática característica de una crítica literaria que podría calificarse como universitaria y que tiene como lector implícito a un lector especializado (en esto se distancia de la antología de Cresseri, quien piensa su libro para "todo público" y se asume además como neófito en la tarea encarada).Cabe aclarar en este punto que el campo de los estudios académicos sobre la poesía local era entonces muy incipiente y se limitaba a breves trabajos publicados hasta el momento por críticos universitarios como Roggiano y Lagmanovich, ya mencionados. ${ }^{25}$ Por tal motivo es posible calificar a

${ }^{25}$ En 1954 Roggiano da a conocer un temprano estudio sobre la poesía del NOA titulado "Seis poetas del Norte argentino" publicado en la revista tucumana Norte, y en 1958 Lagmanovich publica en una revista de la Universidad de La Plata un breve estudio titulado "La poesía actual en Tucumán”. Recién un año después de la publicación de la antología de Bravo Figueroa aparecería otro estudio más extenso de Lagmanovich, "El norte argentino: una realidad literaria" (1966). Se trata, como puede advertirse, de un momento de emergencia de la crítica sobre la poesía y la literatura de Tucumán y de la región. 
este prólogo como un estudio de carácter en verdad pionero (si bien no debe olvidarse un antecedente significativo tal como el configurado por el prefacio de Cónsole, dedicado no obstante a un período muy anterior y carente de un esquema teórico-metodológico como el de Bravo Figueroa, por cuanto corresponde precisamente a una etapa previa a la especialización de la crítica literaria en general y a la constitución de los estudios académicos sobre la poesía local en particular).

Con la consideración de esta antología de Bravo Figueroa se cierra el recorrido propuesto. Interesa retomar, para finalizar, la idea de construcción de una poesía presente en el título de este artículo. Porque si es que hay algo que en efecto puede llamarse "poesía de Tucumán", se trata de una construcción. Y una de las principales y más tempranas operaciones de construcción de esa poesía está dada precisamente por la labor de compilaciones y antologías como las aquí consideradas, que desde los primeros lustros del siglo XX y durante cincuenta años, se ocupan de reunir, organizar, valorar e "historizar" la producción poética de un espacio provincial. Y, en definitiva, de mostrar la existencia de una poesía de Tucumán.

\section{Referencias}

Achugar, Hugo. "Parnasos fundacionales, letra nación y estado en el siglo XIX". Revista Iberoamericana LXIII/178-179 1997: 13-31. Impreso.

Aldonate, Manuel et al. Veinte poetas cantan a Tucumán. Tucumán: Tiempo del Tarco en flor, 1967. Impreso.

Arancet Ruda, María Amelia. "Radiestesia de las provincias en las antologías de poesía argentina". Ed. María Amelia Arancet Ruda. Antologías argentinas. Buenos Aires: Teseo. 2016. Teseo Press. 27 junio 2017. Digital.

Berreta, Hugo A. La Peña El Cardón. Medio Siglo de Cultura Regional. Tucumán: Magna, 2003. Impreso.

Billone, Vicente Atilio. "Primera parte". Vicente Atilio Billone y Héctor Ivo. Marrochi. La actividad poética en Tucumán (1880-1970). Esquema y muestrario. Tucumán: Voces, 1985. 8-49. Impreso.

Bravo Figueroa, Gustavo A. Poesía de Tucumán. Siglo XX. Tucumán: Atenas, 1965. Impreso. 
Catturelli, A. "Itinerario de Manuel Gonzalo Casas". Ed. Guillermo Orce Remis. Ensayos filosóficos. Homenaje al profesor Manuel Gonzalo Casas (1910-1961). Buenos Aires: Troquel, 1963. 9-20. Impreso.

Cónsole, Alfredo. Florilegio de poesías tucumanas. Tucumán: s/d, 1921. Impreso.

Cónsole, Alfredo. "Los poetas tucumanos malogrados por la muerte". Sustancia II/7-8 1941: 653-662. Impreso.

Corvalán, Octavio. Contrapunto y fuga (Poesía y ficción del NOA). Tucumán: Facultad de Filosofía y Letras, Universidad Nacional de Tucumán. 2007 [1987]. Impreso.

Cresseri, José A. Antología poética tucumana en el sesquicentenario. Tucumán: s/d, 1966. Impreso.

Degiovanni, Fernando. Los textos de la patria. Nacionalismo, políticas culturales y canon en Argentina. Rosario: Beatriz Viterbo. 2007. Impreso.

Juliá, Francisco. "Poetas de Tucumán". Cuadrante NOA 5 1977: 29-31. Impreso.

Lagmanovich, David. La literatura del Noroeste argentino. Rosario: Biblioteca, 1974. Impreso.

Leoni Pinto, Ramón. "Historiografía en Tucumán (1880-1950). Autores, obras y problemas". La historia como cuestión. In memoriam Antonio Pérez Amuchástegui. La Rioja: Canguro, 1995. 53-95. Impreso.

Lizondo Borda, Manuel. Tucumán al través de la historia. El Tucumán de los poetas. Tucumán: Edición oficial, 1916. Impreso.

Martínez Zuccardi, Soledad. En busca de un campo cultural propio. Literatura, vida intelectual y revistas culturales en Tucumán (1904-1944). Buenos Aires: Corregidor, 2012. Impreso.

Martínez Zuccardi, Soledad. "El Centenario de la Independencia y la construcción de un discurso acerca de Tucumán: proyectos y representaciones". Prismas. Revista de Historia Intelectual 19 2015: 6787. Impreso.

Martínez Zuccardi, Soledad. "Poesía y azúcar. Los trabajadores azucareros en compilaciones poéticas de Tucumán, Argentina". Acta literaria 50 2015: 133-153. Impreso.

Martínez Zuccardi, Soledad. "La Primera antología poética de Tucumán y el campo literario local durante el peronismo". Gramma 26/55 2015: 32-47.

Núñez, Estuardo. "Teoría y proceso de la antología". Cuadernos americanos CVI/5 1959: 257-267. Impreso.

Orce Remis, Guillermo. "Cómo conocí a Manuel Gonzalo Casas. Una amistad sin tiempo". La Gaceta [Tucumán]. 9 agosto 1987: 4. Impreso.

Orquera, Fabiola. "Crisis social y reconfiguración simbólica del lugar de pertenencia: sentidos de la 'tucumanidad' en un contexto de crisis (1966- 


\section{MARIANO SABA}

1973)". Ese ardiente jardín de la república. Formación y desarticulación de un "campo" cultural: Tucumán, 1880-1975. Ed. Fabiola Orquera. Córdoba: Alción, 2010. 295-318. Impreso.

Primera antología poética de Tucumán. Tucumán: Comisión Provincial de Bellas Artes, 1952. Impreso.

Roggiano, Alfredo. "Seis poetas del Norte argentino". Norte 6 1954: 71-104. Impreso.

Ruiz Casanova, José Francisco. Anthologos: poética de la antología poética. Madrid: Cátedra, 2007. Impreso.

Salazar Anglada, Aníbal. La poesía argentina en sus antologías: 1900-1950.

Una reflexión sobre el canon nacional. Buenos Aires: Eudeba. 2009. Impreso.

Testaverde, Tommaso. El concepto de generación en la actividad crítica y teórica de Oreste Macrí. Tesis de doctorado. Universidad de Granada. 2012. Ugr.es. 15 de abril de 2016. Digital. 